\title{
Energy Optimization of Bharati Vidyapeeth (Deemed to be) University Dhankawadi Campus Pune, INDIA.
}

\author{
Prabhat Kumar, Suyog Hirve
}

\begin{abstract}
This paper represents "Energy Optimization of Bharati Vidyapeeth (deemed to be) university Dhankawadi campus Pune, India”. Generally Educational Institutions are not taken into consideration for energy optimization in our country and around the world which comes in commercial sector. The energy cost is to be managed in academic campus to control the budget and utilize that amount for the growth of the institute. Around10 to $30 \%$ of the energy can be saved in academic campus. The objective of this study is to highlight several opportunities in creating and implementing energy optimization plans within the campus. The current pattern of energy use and safety concern is taken into account. Power quality analyzer is used for measurement and analysis of various electrical parameters at all five substations. Some suggestions are given for efficient use of energy and get benefited for new billing pattern of distribution authorities. The installed electrical facilities and their requirements are taken care like Transformer, APFC panel and capacitors used in the APFC panel.
\end{abstract}

Key words: - Energy Optimization, power quality, Electrical systems, APFC, Electrical safety.

Energy optimization means to reduce energy consumption without making any compromise to magnitude or quality. In other words Energy Optimization means to reduce the amount of Energy consumption without any negative effect on the output of the systems. The day by day energy demand is growing and the energy generation and demand gap is to be reduced. The nation growth depends upon the per capita energy consumption. The electrical energy generated and used in such a way so has less effect to environment. The academic campus energy budget is to, be managed so that they can utilize the amount for other academic activity. Here in this case the campus is multidisciplinary since it has five substation and all have different types of load. For hospital power availability is main concern then power quality taken in to account. A famous quote is that energy saved is energy generated so as much we have to optimize the use of energy. The health care facilities has various sensitive devices and is related to human's life so there won't be any abnormalities' supposed to happen.

Revised Manuscript Received on August 25, 2019.

* Correspondence Author

Prabhat Kumar*, Department of Electrical Engineering, Bharati Vidyapeeth Deemed to be University College of Engineering, Pune, Maharashtra, India

Suyog Hirve, Department of Electrical Engineering, Bharati Vidyapeeth Deemed to be University College of Engineering, Pune, Maharashtra, India

(C) The Authors. Published by Blue Eyes Intelligence Engineering and Sciences Publication (BEIESP). This is an open access article under the CC BY-NC-ND license (http://creativecommons.org/licenses/by-nc-nd/4.0/)

\section{INTRODUCTION}

The academic campus has a vital role in energy optimization. Since there is an electrical department in engineering college and the students learn things and apply that to solve real world problem. As the integration of renewable energy is carried out then the energy consumption is reduced. In this campus there are five critical areas of hospital operation theatre, inter care unit, radiology, casualty, Gynic ward. There are large buildings in the campus upon which solar PV is to be implemented while engineering college has implemented it and on hospital building's roof top 1000KVA solar generation is going to installed.

\section{RELATED WORK}

The authors Pietro Antonio and Scarpino, Francesco Grasso in [1] describes that how the electrical facilities are to be operated reliably under critical load conditions. The load variation and reactive power compensation to the hospital facility in appropriate manner. The hospital has numerous sensitive devices and use nonlinear devices which cause power quality problem so to ensure that real \& reactive power balance is to be done. The author Keerti Kulkarni $\dot{A}$ and Vinay Janardhan Shetty $\dot{A}$ in [2] describes that importance of power quality in the health care facilities. The major power quality problems found in the hospital was voltage and current total harmonics distortions and non zero neutral current. They suggest that power quality monitoring is to be carried out at regular intervals for efficient and reliable use of the electrical facilities which are more sensitive to the power quality problems. THD and neutral current are minimization of by various techniques and use of Unified Power Flow Conditioner which will handle almost all the power quality problems. The authors Ashish Laddha and Abhik Hazara in [3] explains that the integration of renewable energy with the Distributed Generation and their benefits. The annual operating cost with demand side management and implementation of renewable resource of generation considering economy aspects of the campus.. The authors Paula Fonseca, Pedro S. Moura, etc. in [4] explains that how to improve the performance of existing buildings' and reducing the energy cost in economical manner. The educational campuses are having large buildings which consumes significant amount of energy.

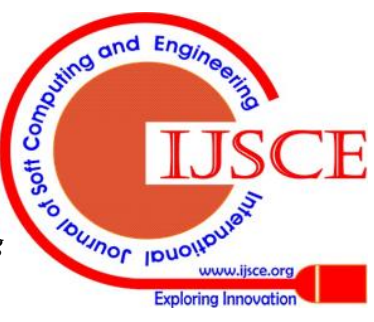




\section{Energy Optimization of Bharati Vidyapeeth (Deemed to be) University Dhankawadi Campus Pune, INDIA.}

The university has limited budget \& rise in energy cost affects that. By integrating the existing supply with the renewable source of generation in parallel is the most suitable way to make the campus zero energy. The authors George Cristian Lazaroiu, Virgil Dumbrava in [5] describes that To make it smart campus Balancing demand / supply and operational parameters for better resource utilization within the campus. The authors Mário César Giacco Ramos and Carlos Márcio Vieira Tahan in [6] describes that the electrical equipments in hospitals which is affected by power quality problems.

\section{ORGANIZATION OF PAPER}

The paper organization as follows first of all the paper discuss about Methodology adopted, analysis of electricity bill \& graphs, then measurements taken by power quality monitoring kit, IEEE standards for current and voltage THD, description of all five sub-station in the campus various data are taken from field and are analyzed, safety concerns it covers all parameters of safety need to be taken care at substations, conclusion after the analysis of all the data and recommendation are given to them for better operation and optimized use of energy within the campus.

\section{METHODOLOGY ADOPTED}

The main incoming supply from new parvati sub-station (220KV) comes to padmawati switching sub-station (22/22KV) then Gulab nagar $(22 \mathrm{KV})$ \& Balaji nagar $(22 \mathrm{KV})$. After that supply of MSEDCL comes to all five substations in the campus and HT switchgears at all substations in the college campus. Medical College \&Students Hostel are looped together via RMU. All five Sub-Station has feeder voltage $22 \mathrm{KV}$.

The possibility of integrating renewable energy sources with the utility supply system. Since solar panels are mounted on some of the colleges buildings like Engineering, polytechnique, work shop buildings etc. Safety concerns of the systems. The power availability is the main concern in the Bharati hospital then power quality comes into picture.

At students hostel sub-station actual MD is around 300KVA \& IRSHA sub-station actual MD is 155KVA so the transformers are running under load condition. As we know that distribution transformer has maximum efficiency at or near full load condition.

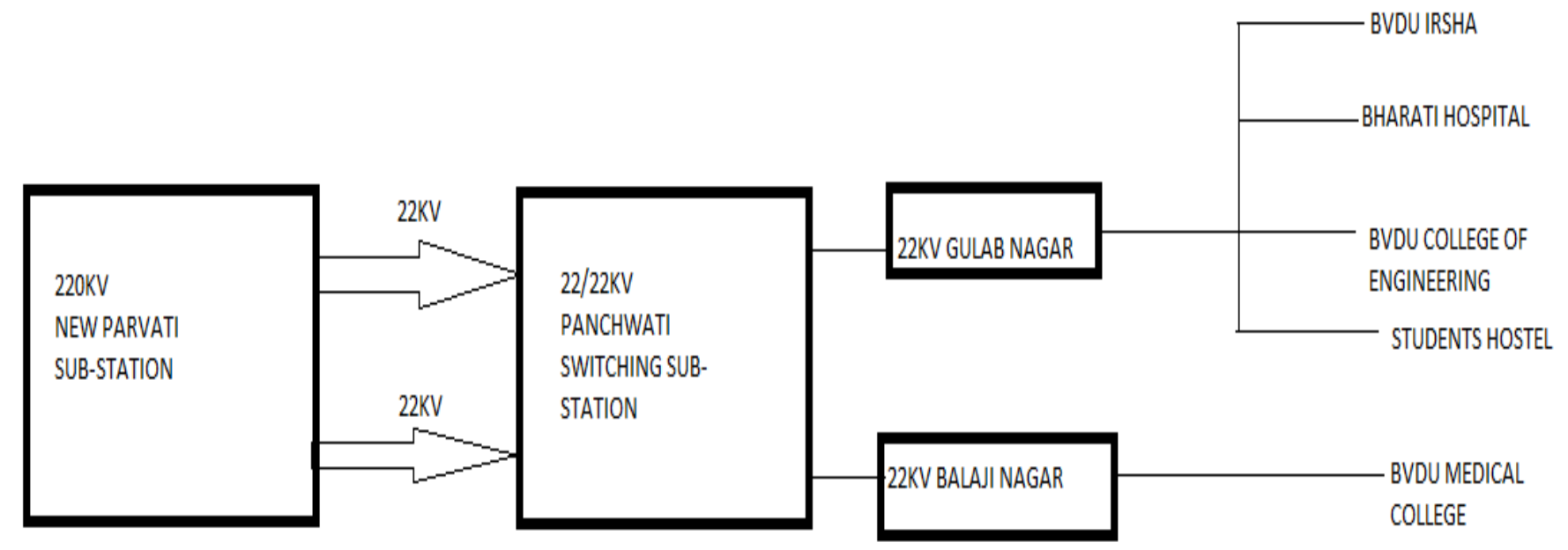

Figure 1:- power supply from main distribution to the campus sub-stations

Retrieval Number:C3268099319/19@BEIESP

DOI:10.35940/ijsce. C3268.099319

Journal Website: www.ijsce.org
Published By:

Blue Eyes Intelligence Engineering

15

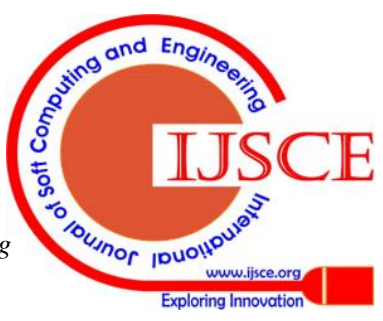




\section{ANALYSIS OF ELECTRICITY BILLS}

The analysis of electricity bills for 12 months is carried out to all five sub-stations in the campus from January 2018 to December 2018.

Demand charges per KVA till March 2019 is 250Rs. April2019 to august 2019 is 270Rs.and September 2019 to till now is 350Rs.

MSEDCL provide 7\% incentives to bill amount for power factor 0.95 to 1 and for power factor 0.90 to 0.95 no incentives no penalty. While power factor below 0.90 penalties are charged by MSEDCL.

1. For Bharati Hospital sanctioned Demand is 800KVA and bill demand is 601KVA to 722KVA. The actual demand is equal to bill demand.

Incentives are given for good power factor because it has maintained above 0.95 .

2. For College of Engineering sanctioned demand is 250KVA till June 2018, from july02018 it is increased to $350 \mathrm{KVA}$ as the load increased. Solar panel is mounted on the college of engineering buildings so the energy demand is reduced now from 43143kwh to $1080 \mathrm{kwh}$.

3. For Medical College Sub-station sanctioned demand is $500 \mathrm{KVA}$ and Bill demand is $315 \mathrm{KVA}$ to $281 \mathrm{KVA}$ which is equal to actual demand.

Incentives are given for good power factor. From January 2018 to September 2018 power factor is above 0.98 after that it is 0.91 which is to be improved to get incentives from MSEDCL.

4. For students hostel sanctioned demand is 683KVA. Bill demand is 210KVA to 300KVA which is less than the half of the sanctioned demand .since he has to pay at least $50 \%$ of the sectioned demand. Here actual demand is less than the $50 \%$ of the sectioned demand. It means that he is paying more than consumption of energy. From January 2018 to December 2018 extra KVA charged is payed to MSDCL is 42KVA to $112 \mathrm{KVA}$. On average 24825Rs.per month is paid extra to MSDCL. On one year $24825^{*} 12=2$, 97,900 Rs. is given in 2018. This amount should be utilized in some valuable things in campus for development of the institute.

Power factor is not proper so no incentives is given to it because of capacitor banks are used is not properly selected in size.

5. For IRSHA Sub - station sanctioned demand is 450KVA and bill demand is $225 \mathrm{KVA}$ which is $50 \%$ of the sanctioned demand. Actual demand is less than the bill demand which is 101KVA to 155KVA from January to December 2018. Every month Extra KVA is 70 to 123 is paid it means every month he is paying extra chares per KVA.

Every month extra KVA charge is 27,638 Rs .for one year 2018 it is $12 * 27,638=3,31,656$ Rs. Amount was given to MSDCL which is to be utilized for the growth of the institute for other valuable things such as extra teacher, some new instruments for research works etc.

\section{Extra KVA charges paid to MSDCL on monthly basis}

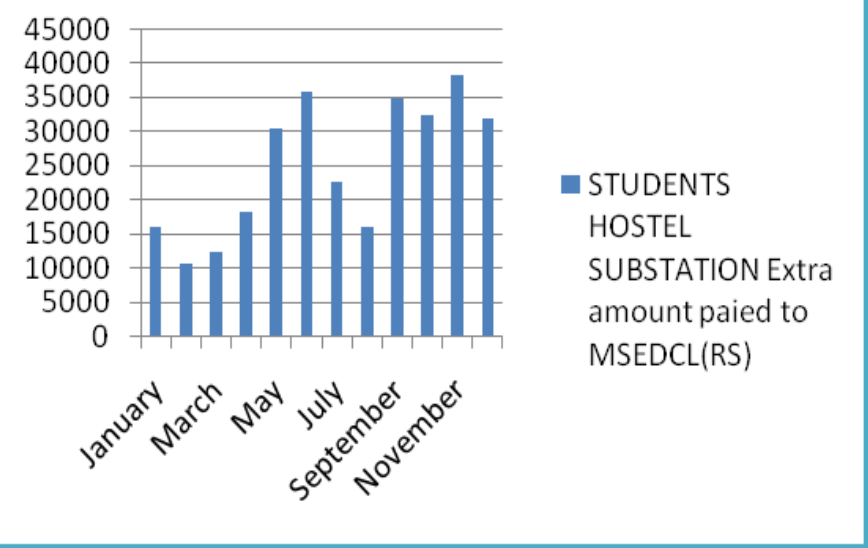

Figure 2:- students Hostel Substation Extra amount paid to MSEDCL per month in 2018

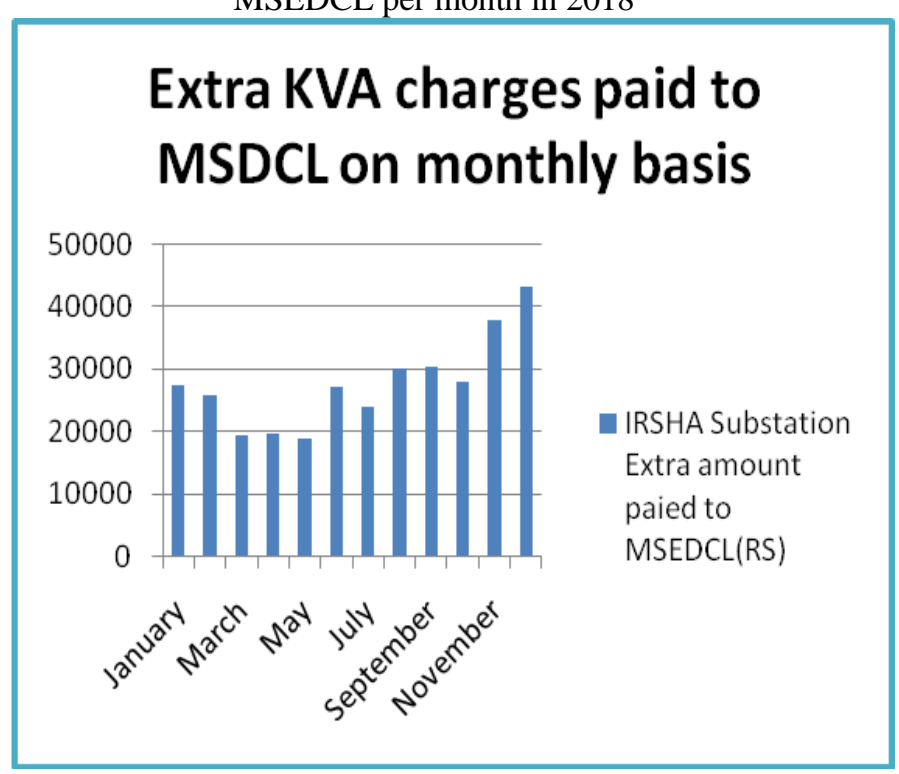

Figure 3:- IRSHA Substation Extra amount paid to MSEDCL per month in 2018

\section{MEASUREMENTS TO BE TAKEN}

Various Electrical Parameters are measured with the help of Power Quality Analyzer of Rishabh Instrumentation Power Quality Monitoring Kit, like Voltage; current, power PF; Harmonics etc. are measured at various points. The main power quality problems found in Bharati Hospital were harmonic distortion (THD) value and Over Compensation of Reactive Power. By this devices which are more sensitive to over voltage may get damaged. Since over compensation of Reactive Power cause increase in voltage to the system. There are three DG 380KVA of each is installed here for Backup power and all are synchronized together to share the load.

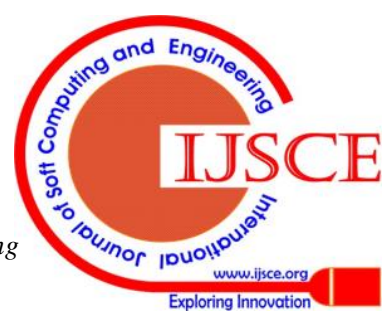


But I noticed that one generator is unable to synchronize with other two due to this problem non critical area load is switched off and then it is switched on when the third generator started on. This problem happens due to not proper maintenance of the DG. On the other hand while switching off to the non critical areas panel switch is not work for that manually panel is to be open and then switched is on/ off action is done.

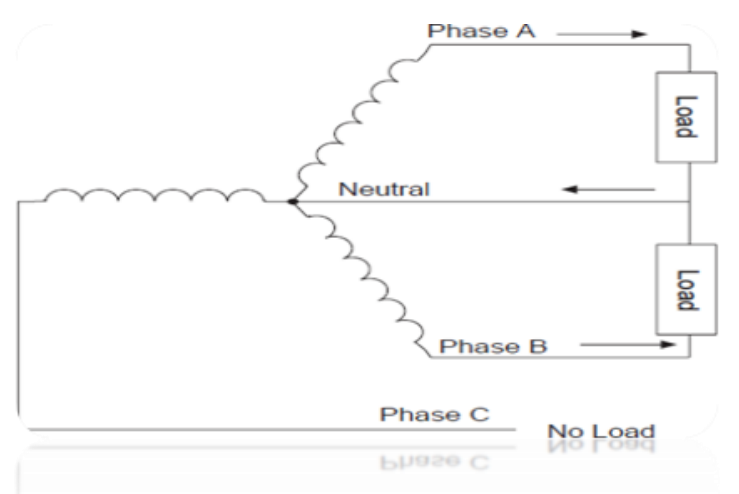

Figure 4:- Unbalanced line loads and neutral current. The analysis of the electrical system in the campus highlights some major area where proper attention is required. At some substations THD and unbalanced load currents. Since both of that contribute to flow of neutral current as it flow back to the transformer neutral resulting in heating of the neutral cable. The neutral current increases As the THD increase.

\section{IEEE STANDARDS}

The IEEE Standerd-519 has harmonic limits of voltage is 5\% THD and $3 \%$ of the fundamental voltage for any single harmonic. The healthcare Equipments are more sensitive to harmonics (less than 3\% Voltage THD). The maximum short circuit current at PCC and IL is maximum load current at PCC.

Where Isc $=$ maximum short circuit current at PCC And IL = maximum load current at PCC.

\begin{tabular}{|c|c|c|c|}
\hline & 兽莺 & 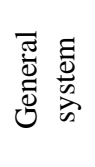 & 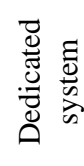 \\
\hline Notch depth & $10 \%$ & $20 \%$ & $50 \%$ \\
\hline \% THD voltage & $3 \%$ & $5 \%$ & $10 \%$ \\
\hline
\end{tabular}

Table 1: Maximum Voltage harmonic distortion

\begin{tabular}{|c|c|}
\hline$\left(\mathrm{I}_{\mathrm{SC}} / \mathrm{I}_{\mathrm{L}}\right)$ & $\% \mathrm{THD}$ \\
\hline$<20$ & $5 \%$ \\
\hline $20-50$ & $8 \%$ \\
\hline $50<100$ & $12 \%$ \\
\hline $100-1000$ & $15 \%$ \\
\hline$>1000$ & $20 \%$ \\
\hline
\end{tabular}

Table 2: Maximum Current harmonic distortion

For current distortion limit definition, IEEE Std-519 has a short circuit ratio for the voltage distortion of the system. at the point of common coupling The short circuit ratio (ISC/IL) is the ratio of short circuit current (ISC) with the utility, to the customer's maximum load or demand current (IL).

\section{DESCRIPTION OF ALL FIVE SUB-STATION IN THE CAMPUS}

\section{Bharati Hospital:-}

At Bharati Hospital the reactive power is over compensated on light load condition at night from around 12 O'clock to 3 O'clock. This happens due to capacitors used in the APFC panel is not proper in size. It means the power compensation required at light load condition is not matching with the available capacitor KVAR individual rating. So APFC Panel gives command to relay to switch on the minimum rating of capacitor which is more than required.

Due to over compensation in KVAR overvoltage occurs so sensitive devices in the hospital got damaged. Current THD are approx 10 to $12 \%$ in 3phase at light load condition due to UPSC used in every critical section of the hospital. At light load condition in the night when UPSC are mostly idle then it injects more harmonics. The current neutral current increases as the THD increases. This may lead to increase the losses and heating of transformer.

College Of Engineering:-

At College Of Engineering from power quality analyzer we get to know that the two phases R\&Y share equal load 208Amp. \& 209Amp respectively while in the B phase 177Amp. Which causes neutral current to flow up to 27Amp. Some of the load is shafted to B phase from Y phase so that all three phase got equal load share and flow of neutral current is to be minimized. The THD current is varying from $5 \%$ to $9 \%$ which is to be reduced within the standard limits and power factor is 0.96 to 0.98 that should be improved for better efficient use of electricity.

\section{Medical college:-}

At Medical College from power quality monitoring kit we got to know that the neutral current is 71Amp. The all three phases R, Y, B share load of 383Amp, 348Amp, 331Amp. Some load is shifted to $B$ phase from $R$ phase to reduce the neutral current flow. While the capacitor used in APFC is not properly working as the load varies and KVAR is to be maintained. As the load varies the reactive power compensation will vary accordingly. Since we have to maintain strictly unity or approx unity power factor for lagging as well as leading power factor penalty are charged by MSEDCL. The current THD is $8 \%$ to $12 \%$ which is reduced to standard level because medical college has various sensitive devices which is sensitive to it. The power factor is with and without capacitor bank is measured which is approx same up to $0.96 \%$.

\section{IRSHA:-}

At IRSHA sub-station due to unbalance load flow the Instrument called BIO Safety used for some research work got damaged its main input chip. The cost of the damaged chip is $45 \mathrm{~K}$ and there are four BIO Safety Instruments are equipped cost of one machine is around 3.5 to 4 lacks and cost of damaged parts is $45 \mathrm{~K}$. Till now

there are 3 instruments got damaged so the total cost is $3 * 45=1,35,000$ Rs. The Instrument is used randomly. The Neutral current reaches to around 45A.

Published By: Blue Eyes Intelligence Engineering

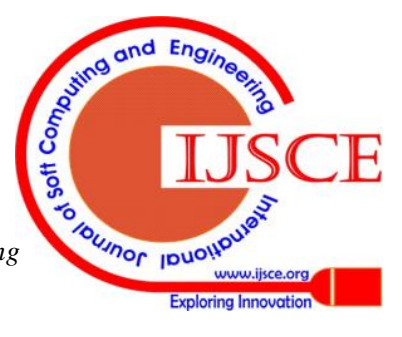


The Neutral current are not exceed its limit while DG is operating. Since the DG has given limited load which is balanced. The Sub-station is installed in October 2015.Transformer servicing and testing is done in March 2019 and maintenance cost is $68 \mathrm{~K}$ in which neutral and earth is checked. The loads in all three phases R, Y \& B are 191A, $125 \mathrm{~A} \& 152 \mathrm{~A}$ and neutral current is 55Ampere at 03:19 PM. The voltage THD is up to $6 \%$ while the current THD is up to $21 \%$. For BIO Safety Instruments a stabilizer is used for voltage stabilization. Measurement of voltages is taken by digital millimeter which is respectively phase-neutral $230 \mathrm{~V}$ phase- earth $230 \mathrm{~V}$ and neutral - earth $1.0325 \mathrm{~V}$. But high neutral load current $64 \mathrm{~A}$ is still at main panel. While the BIO safety Instruments are safe by the use of stabilizer.

\section{Students Hostel:-}

At Students Hostel Power factor is very poor instead of APFC PANEL is used. The capacitor used in APFC panel is not in proper in ranges of size. The minimum to maximum ranges of capacitor is to be in proper KVAR rating. Since MSEDCL charge for lead as well as lag in PF. To receive incentives and avoid penalties strictly maintain unity PF. Therefore capacitor ratings of APFC panel are properly selected.

\section{Safety concerns:-}

At Bharati Hospital Panel room is very much congested and one cannot easily access to all-around the panel. Ventilation is also a concern for proper ventilation is to be provided for the Distribution panel switches and associated devices. DG set room has also ventilation and safety issue. In case of any undesirable phenomenon happens then no body get harm and if anyone is there inside the room can get easily come out which is not here in this case.

Electrical hazards to minimize the risk of accidents like fire due to short-circuiting.

College of Engineering panel room and DG room has less ventilation and not proper for safety concern. Since in case of any accident one cannot come out easily and re-installation is not that much easy.

Medical college panel room is not accessible easily all-around.

Students Hostel panel room is located far away and the location is such tidies so one cannot go there easily at less time in case of any accident happens. Ventilation is also very bad and accessing the panel room is very much difficult. It is very dark and less ventilated room.

IRSHA panel room is in the basement of the building which has less ventilation and in case of any accident occurs then it is very difficult to re- install the panel. Since very small door is only access to the room.

\section{ACKNOWLEDGEMENT}

The authors wish to acknowledge the constant support given by the department of Electrical (power system) Engineering from Bharati Vidyapeeth (Deemed to be) university, College of Engineering, Pune, and all the electricians' at all five substations in the campus.

\section{ConClusions}

This paper describes the energy optimization in academic campus in India. From the Electricity Bills analysis I have noticed that actual MD (KVA) is less than Bill Demand which is to be taken into consideration for reduction of bill amounts. Specially sanctioned demand at IRSHA \& students hostel is more that should be reduced. Since the actual demand is less than the bill demand which is $50 \%$ of the sanctioned demand. Power Factor at student hostel substation is to be improved to get the incentives from MSDCL. In the Bharati hospital capacitor banks are over compensating the reactive power in the night when the substation is at less loads and UPS systems are injecting more harmonics in the night's .How many sub-stations paying more kVA charges. Bill Demand and actual demand is not should have much difference. APFC panel are installed at every sub-station but the selection of capacitor ratings is not proper due to this at light load condition over compensation. None zero neutral current and THD values are main issue at the substations within the campus.

\section{RECOMMENDATIONS}

For next billing pattern of MSEDCL KVAH will be the billing unit so capacitor sizes in KVAR chosen such that it maintain unity or approx unity power factor. The next billing pattern is going to implement from financial year 2020 .

So that actual consumption is equal to billing unit. Safety concern is to be taken care to handle any accidents at any condition and operators safety also.

Bharati Hospital supply coming from Gulab Nagar 22KV feeder which is to be looped with the another supply coming from Balaji Nagar 22KV feeder to the campus to other sub-stations so that in case of any emergency occurs to the existing feeder then backup supply is fed via another feeder. Since Bharati hospital is related to hymens life and in case of any emergency to existing feeder1 then one cannot continue the supply on DG backup it will be more costly. Therefore I have suggested going for loop with another feeder.

Load curve is adjusted by shifting the off peak loads.

IRSHA and Students hostel Sub-Station sanctioned demand is more which should be reduced. Since them both substations are paying more than actual consumption because the actual demand is less than bill demand.

An active filter or a passive filter is to be implemented for the THD reduction in system. Unified Power Flow Conditioner (UPFC) is to be installed to mitigate almost all power quality problems in the near future. Installation of custom power device like, Unified Power Flow Conditioner which will tackle almost all the power quality problems can be thought of in the near future.

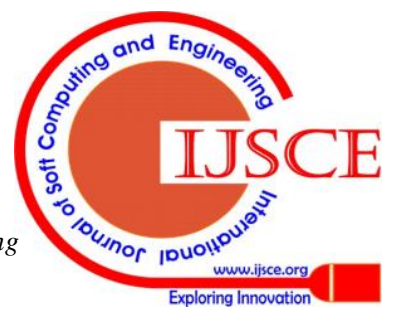


Energy Optimization of Bharati Vidyapeeth (Deemed to be) University Dhankawadi Campus Pune, INDIA.

\section{REFERENCES}

1. Pietro Antonio Scarpino, Francesco Grasso "Analysis of Complex Hospital Electrical Systems” 2017 AEIT International Annual Conference

2. Keerti KulkarniÄ and Vinay Janardhan Shetty "Power Quality Issues in Healthcare Centre" International Journal of Current Engineering and Technology Vol.4, No.3 (June 2014)

3. Ashish Laddha Abhik Hazara and Mausumi Basu "Power production strategies from renewable energy resources in a hospital campus considering economic aspect" 2016 IEEE 7th Power India International Conference (PIICON)

4. Paula Fonseca, Pedro S. Moura , Humberto Jorge and Anibal de Almeida "Achieving university campus sustainability with nearly zero energy building retrofits"

5. George Cristian Lazaroiu, Virgil Dumbrava, Mihnea "Smart Campus-an energy integrated approach" 2015 International Conference on Renewable Energy Research and Applications (ICRERA)

6. Mário César Giacco Ramos and Carlos Márcio Vieira Tahan "An Assessment of the Electric Power Quality and Electrical Installation Impacts on Medical Electrical Equipment Operations at Health Care Facilities"

\section{AUTHORS PROFILE}

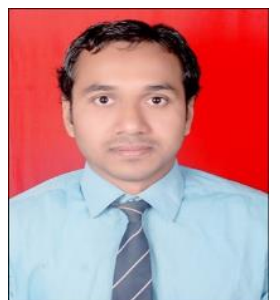

Prabhat Kumar Graduated in Electrical engineering from the. Bharati Vidyapeeth (Deemed to be) University College of Engineering, Pune, Maharashtra, India and presently a Master of Technology student of electrical engineering with power system as special subject for the Bharati Vidyapeeth (Deemed to be) University College of Engineering, Pune, Maharashtra, India.

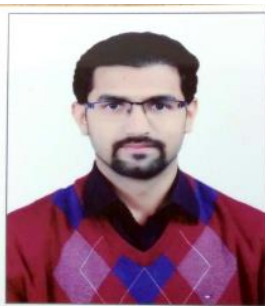

Mr. Suyog S. Hirve graduated from Pune University and completed M.E in Power System. His Area of interest includes Renewable Energy Sources, Energy Storage Devices. He is currently working as Assistant Professor in Electrical Engineering Department of Bharati Vidyapeeth Deemed to be University College of Engineering, Pune, India.

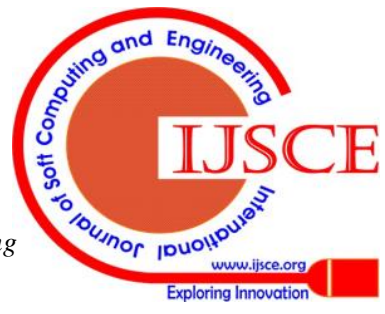

